\title{
Axillary Approaches to Brachial Plexus Block: A Comparison of Stimulator-guided Peripheral Nerve Block with and Without Ultrasonography Techniques
}

\author{
(D) Demet Altun, (D) Güray Dedebek, (D) Meltem Savran Karadeniz, (D) Emine Aysu Şalvız, (D) Mehmet Tuğrul \\ istanbul University, Istanbul Faculty of Medicine, Department of Anesthesiology, istanbul, Turkey
}

\section{Abstract}

Objective: This study aims to compare stimulator-guided peripheral nerve block with and without ultrasonography techniques to investigate the block procedure time, sensory and motor block onset time, pain related to the block procedure-related pain, and anesthesia-related complications.

Methods: Patients were randomized into two groups: The nerve stimulator (NS)-guided technique group ( $\mathrm{n}=30$ ) and the NS with ultrasound $(\mathrm{NU})$-guided technique group $(\mathrm{n}=30)$. One-quarter of the solution prepared with prilocaine $2 \%$ and lidocaine $2 \%$ with the height/ 5 formula was injected around each nerve after receiving a motor response between 0.3-0.5 mA.

The block procedure time, sensory and motor block onset time, the number of skin punctures, procedure-related preoperative complications, procedure-related postoperative complications, and visual analog scale (VAS) (0-10) scores were recorded.

The heart rate, systolic arterial pressure, diastolic arterial pressure, mean arterial pressure, and peripheral oxygen saturation values were noted at $0,5,10,15,30,45,60,120$, and 180 minutes.

Results: The block procedure time was similar between them $(p>0.05)$. The number of skin punctures $(p=0.001)$ and VAS $(p<0.045)$ were significantly higher in the NS group. The sensory and motor block onset times were significantly similar ( $p>0.05)$ except for the motor block of musculocutaneous nerve onset time $(p<0.05)$. Although the success rate was higher in the NU group, there was no statistically significant difference between the groups ( $p>0.05)$. The number of complications was significantly higher in the NS group ( $p<0.05)$.

Conclusion: Using ultrasonography with the NS in the axillary approach to brachial block improves the success rate with a lower incidence rate of complications.

Keywords: Brachial plexus block, motor block, nerve stimulator, sensory block, ultrasound

\section{INTRODUCTION}

A brachial block via the axillary approach is a common technique to provide anesthesia for upper extremity surgery. Peripheral nerve blocks offer numerous advantages, such as providing better postoperative pain scale scores, lower incidences of nausea and vomiting, shorter recovery time, early mobilization, decreased hospital stay, more stable hemodynamic results, and greater patient satisfaction. For the past decades, the nerve stimulator (NS) had been the gold standard for nerve localization in regional anesthesia. However, with recent developments in high-frequency imaging, using ultrasound (US) technology has significantly increased nerve localization.

A US-guided peripheral nerve block can be applied more successfully, easily, safely, and painlessly. This technique 
enables direct visualization of nerves and surrounding anatomy, continuous observation of the needle tip, and local anesthetics distribution. However, complications occur during the US alone. Therefore, using a combination of different techniques is recommended.

This study aims to compare peripheral nerve block guided with the NS with and without ultrasonography to investigate the time to perform the block, sensory and motor blocks onset time, pain related to the block procedure, and complications related to anesthesia.

\section{METHODS}

After obtaining Institutional Ethics Committee approval was received for this study from the Local Ethics Committee of İstanbul University, Medical Faculty of istanbul (decision date: 12/04/2013, decision no: 412), a total of 60 patients undergoing elective upper extremity surgery between 18-70 ages and American Society of Anesthesiologists (ASA) I-IV status were enrolled in this prospective randomized study. Before conducting the study, all patients provided their informed consent. Then, they were randomly divided into two groups according to a randomization table: the NS-guided technique group and the NS with ultrasound (NU)-guided technique group. Patients with coagulation disorders, a history of allergy to local anesthetics, and neuromuscular and psychiatric diseases, a history of peripheral neuropathy, and patient refusal were the study's exclusion criteria.

After arrival at the operating room, standard monitoring was used, including non-invasive arterial blood pressure, heart rate $(\mathrm{HR})$, and pulse oximetry, and an intravenous catheter was placed to the forearm contralateral to the operating arm 30 min before the block, standard premedication was given intravenously (2 $\mathrm{mg}$ ) to all the patients. Then, the patients were placed supine with the arm abducted 90 degrees.

The skin sterilization was made with chlorhexidine antiseptic solution.

In all patients, the block procedure was done by an experienced anesthesiologist applying the axillary approach technique.

Systolic arterial pressure, diastolic arterial pressure, mean arterial pressure, $\mathrm{HR}$, and peripheral oxygen saturation $\left(\mathrm{SPO}_{2}\right)$ was recorded in $0^{\text {th }}, 5^{\text {th }}, 10^{\text {th }}, 15^{\text {th }}, 30^{\text {th }}, 45^{\text {th }}, 60^{\text {th }}, 120^{\text {th }}$, and $180^{\text {th }}$ seconds.

In the NS group, after palpating the axillary artery's pulse at the attachment of the major pectoral muscle, the nerve was localized using a 21 gauge, $100 \mathrm{~mm}$ needle connected to the negative lead of the NS (Stimuplex ${ }^{\circledR}$ HNS B/BRAUN). The NS was set at a pulse duration of $0.1 \mathrm{~ms}$, a current intensity of $1.5 \mathrm{~mA}$, and a frequency of $2 \mathrm{~Hz}$. The stimulator flow was deducted after receiving the proper muscle contraction (wrist flexion for the nervus medianus, ulnar deviation for the nervus ulnaris, wrist extension for the radial nerve, and elbow flexion for the nervus musculocutaneous).

In cases of motor responses between 0.3-0.5 mA, after determining that there was no blood aspiration, an equal amount of a prepared solution containing a mixture of prilocaine $2 \%$ and lidocaine $2 \%$ was injected around each nerve by the axillary artery. This volume was one-quarter of the solution prepared earlier, with prilocaine $2 \%$ and lidocaine $2 \%$ using the height $/ 5$ formula.

In the NU group before the procedure, the US settings were set at depth: 3-5 cm, frequency: 8-14 Hz, and the stimulator parameter was set at $1.5 \mathrm{~mA}, 2 \mathrm{~Hz}$, and $0.1 \mathrm{~ms}$. The US probe was covered with a sterile sheath, coated with a sufficient amount of gel, and placed on the short axis of the humerus' insertion point on the pectoralis major muscle.

After recognizing the pulsatile axillary artery by gentle suppression of the probe, a $100 \mathrm{~mm} 21 \mathrm{G}$ needle was inserted into the skin at a $45^{\circ}$ angle with the long axis approach.

When the needle was visible under the probe, it was directed to the target nerves. After obtaining the proper muscle contraction (wrist flexion for the nervus medianus, ulnar deviation for the nervus ulnaris, wrist extension for the nervus radialis, elbow flexion for the nervus musculocutaneous), the flow of the simulator was deducted. In cases of motor responses between 0.3-0.5 mA, after determining that there was no blood aspiration, an equal amount of a prepared solution containing a mixture of prilocaine $2 \%$ lidocaine $2 \%$ was injected around each nerve by the axillary. This volume was one-quarter of the solution prepared earlier, with prilocaine $2 \%$ and lidocaine $2 \%$ using the height $/ 5$ formula.

In all patients, the block procedure time, onset time of sensory and motor blocks, the number of skin punctures, procedurerelated preoperative complications, procedure-related postoperative complications, visual analog scale (VAS) (0: No pain; 10: Worst imaginable) scores were recorded.

The block procedure time: Time from skin contact with either the US probe or the needle to the injection of the local anesthetic solution.

The onset time of the sensory and motor block: From the end of the injection of the local anesthetic solution, the onset time 
for the sensory block was evaluated with the pinprick test. For the motor block, the radial, ulnar, median, and musculocutaneous nerves were evaluated with the medical research council scale at $3,5,10,15,20,25,30$, and 40 min, respectively.

\section{Sensory Block}

0: Normal sensation, 1: Decreased sensation (analgesia), 2: Complete sensory block (anesthesia).

\section{Visual Analog Scale Score}

When the sensory and motor blocks were completely performed, pain levels were assessed during the verbal pain scale.

0-2: No pain, 3-4: Mild pain, 5-6: Moderate pain, 7-8: Severe pain, 9-10: Excruciating pain.

\section{Complications}

Procedure-related preoperative complications: vascular puncture, hematoma, paresthesia, allergic reaction.

Procedure-related postoperative complications: After 24 hours, neurological complications, such as paresthesia and motor weakness, were evaluated.

\section{Block Success was Evaluated as}

Successful block: The operation was completed under block without any additional analgesia.

Partial block: The need for additional analgesia.

Failed block: General anesthesia was needed, or the procedure duration exceeded $20 \mathrm{~min}$.
Insufficient block: In pain during the surgery, sedo-analgesia was administered with a bolus of $0.03 \mathrm{mg} \mathrm{kg}^{-1}$ midazolam IV and remifentanil infusion $0.05 \mathrm{mcg} \mathrm{kg}^{-1} \mathrm{~h}^{-1}$ under $3 \mathrm{~L} \mathrm{~min}^{-1}$ oxygen. If $\mathrm{SPO}_{2}<90 \%$ or apnea was longer than $20 \mathrm{sec}^{-1}$ under sedoanalgesia, general anesthesia was administered.

\section{Statistical Analysis}

All data were evaluated with Statistical Package for Social Sciences for Windows v. 16.0 program. Data are given as mean \pm standard deviation. Categorical data were compared with the chi-square test and continuous data with Fisher's exact test. P values $<0.05$ were considered significant.

\section{RESULTS}

During the study, 70 patients were scheduled. Four patients refused to participate in the study, six patients did not meet the inclusion criteria, and 60 patients were enrolled in this investigation (Figure 1). Demographic data of the patients were not significantly different between the two groups (Table 1).

\begin{tabular}{|l|l|l|l|}
\hline \multicolumn{2}{|l|}{ Table 1. Patient demographic data } \\
\hline & $\begin{array}{l}\text { NS group } \\
(\mathbf{n}=30)\end{array}$ & $\begin{array}{l}\text { NU group } \\
(\mathbf{n}=30)\end{array}$ & $p$ value \\
\hline Age & $44.8 \pm 12.8$ & $48.2 \pm 13.4$ & 0.32 \\
\hline Weight $(\mathrm{kg})$ & $76.3 \pm 9.9$ & $78 \pm 14.7$ & 0.61 \\
\hline Height $(\mathrm{cm})$ & $163.9 \pm 11.2$ & $167.6 \pm 11.9$ & 0.22 \\
\hline $\begin{array}{l}\text { Data were given as mean } \pm \text { standard deviation. NS: Nerve stimulator, NU: Nerve } \\
\text { stimulator with ultrasound }\end{array}$ \\
\hline
\end{tabular}

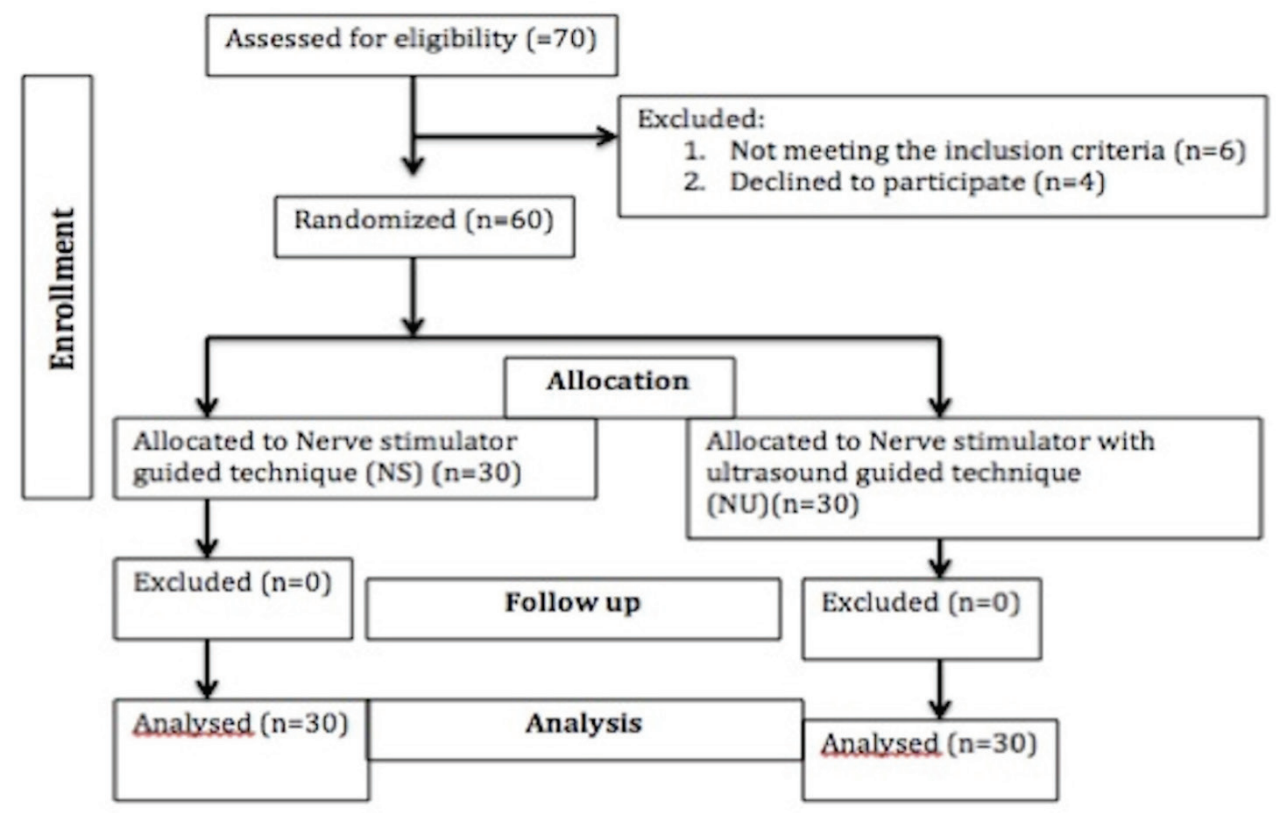

Figure 1. Flow diagram of the study 
There were no significant differences in operation time and time to perform the block between the two groups (Table 2).

The number of skin punctures and VAS scores was significantly higher in the NS group than in the NU group $(p=0.001, p<0.05)$ (Table 2).

There was not a statistically significant difference between the two groups in the usage of a total local anesthetic volume $(p>0.05)$ (Table 2).

While there was no statistically significant difference in sensory and motor onset times of the ulnar nerve, the median nerve, and the radial nerve $(p>0.05)$ in the NU group, there was a significant difference in the motor onset time of the musculocutaneous nerve in the NS group $(p<0.05)$ (Figure 2).

There were no differences in the patients' hemodynamic values between the two groups during the procedure $(p>0.05)$.

Although the success rate was higher in the NU group, there was no statistically significant difference between groups ( $p>0.05)$ (Table 3).
While a total of 19 complications were seen in the NS group during the block procedure, four complications were observed in the NU group ( $p=0.0001)$ (Table 3); and complete recovery of sensory and motor function was observed in all studied patients.

\section{DISCUSSION}

In this study comparing the peripheral nerve block guided with the NS with and without ultrasonography, no significant difference was observed to perform the block between the two groups. While the two groups' data consistently showed similar success rates, the complication rates and VAS scores were better in the US group.

In recent clinical studies, it was demonstrated that, in peripheral nerve blocks, the success rate was influenced by the local anesthetic solution type, concentration, and volume, and by patients' demographic data (1-3). In our study, patients' demographic data were similar, and we administered equal doses of the local anesthetic solution to each patient to provide the standardization between the groups.

\begin{tabular}{|l|l|l|l|}
\hline Table 2. Data on the axillary approach to brachial plexus block & NU group $(\mathbf{n}=3 \mathbf{0})$ & $\mathbf{p}$ value \\
\hline Operation time $(\mathbf{m i n})$ & NS group $(\mathbf{n}=\mathbf{3 0})$ & $59.3 \pm 29.8$ & 0.13 \\
\hline Time to perform the block $(\mathbf{m i n})$ & $72.3 \pm 35.5$ & $9 \pm 3.6$ & 0.15 \\
\hline The number of skin punctures & $10.7 \pm 5.4$ & $1.5 \pm 0.7(1-3)$ & $0.001^{*}$ \\
\hline Usage of total local anesthetic volume $(\mathbf{m L})$ & $2.3 \pm 1(1-4)$ & $33.5 \pm 2.3$ & 0.47 \\
\hline VAS score $(\mathbf{0}-\mathbf{1 0})$ & $33.5 \pm 2.3$ & $2.6 \pm 2.1$ & $0.045^{*}$ \\
\hline *Data are given as mean \pm standard deviation and minimum-maximum. NS: Nerve stimulator, NU: Nerve stimulator with ultrasound, VAS: Visual analog scale \\
\hline
\end{tabular}

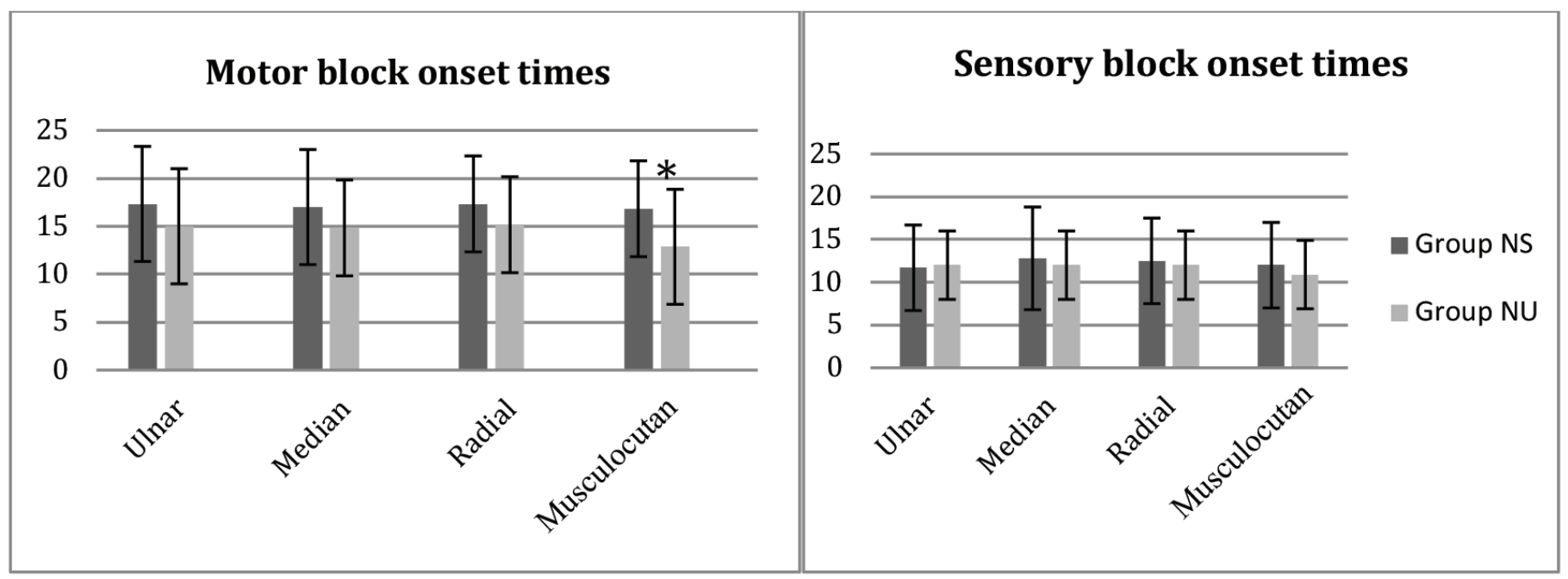

Figure 2. Motor and sensory block onset times of groups

${ }^{*} \mathrm{p}<0.05$ The motor onset time of the musculocutaneous nerve in the NU group was significantly shorter than the NS group. NS: Nerve stimulator, NU: Nerve stimulator with ultrasound 


\begin{tabular}{|c|c|c|}
\hline & $\begin{array}{l}\text { NS group } \\
(n=30)\end{array}$ & $\begin{array}{l}\text { NU group } \\
(n=30)\end{array}$ \\
\hline \multicolumn{3}{|l|}{ Success rate } \\
\hline Successful block & $23(76.6 \%)$ & $28(93.2 \%)$ \\
\hline Partial block & $7(23.3 \%)$ & $2(6.6 \%)$ \\
\hline Failed block & 0 & 0 \\
\hline \multicolumn{3}{|l|}{ Complications } \\
\hline Vascular puncture & 8 & 0 \\
\hline Hematoma & 2 & 0 \\
\hline Paresthesia & 9 & 4 \\
\hline \multicolumn{3}{|c|}{$\begin{array}{l}\text { Values are numbers of patients. NS: Nerve stimulator, NU: Nerve stimulator with } \\
\text { ultrasound }\end{array}$} \\
\hline
\end{tabular}

Our study found no significant difference in the time to perform the block between the two groups. Cataldo et al. (4) showed that using the time was faster using the US popliteal block than with the NS. In Chan et al.'s (5) study, US was used with the NS to perform the block. They observed that an additional technique extended the time to perform the block.

The application time to perform the block varied with the different approaches used (6). Song et al. (7) demonstrated that performing the brachial block via the infraclavicular approach was faster than the axillary approach. This difference in the processing time was explained by fewer injection requirements in the infraclavicular approach. Imasogie et al. (8) performed the US-guided axillary approach brachial plexus block using four nerve injections in $10.9 \mathrm{~min}$ and with two nerve injections in $7.86 \mathrm{~min}$.

Our study performed four nerve injections in $10.7 \mathrm{~min}$ in the NS group and 9 min in the NU group.

In our study, the number of skin punctures and VAS scores was significantly higher in the NS group than in the NU group. While VAS scores were not an objective criterion, the relationship between the skin punctures was demonstrated in different studies $(9,10)$. On the other hand, Cataldo et al. (4) observed that while the number of skin punctures was higher in the US group, patient satisfaction was much better. This finding is likely because the time to perform the block was shorter when using the US.

Several trials demonstrated that the onset times of motor and sensory blocks were shortened by utilizing the US in peripheral nerve blocks $(11,12)$. Our results showed that while the onset times of motor and sensory blocks were shorter in the US group, there was no significant difference except musculocutaneous nerve block. The smaller diameter of the musculocutaneous nerve than other nerves can make localization difficult with NS alone. It is possible to obtain a similar effect on onset times as in our study with US and NS technique in experienced hands (9).

The local anesthetic solution's characteristics used, dose, and concentration affect the onset time of action. Casati et al. (9) using $20 \mathrm{~mL}$ ropivacaine $0.75 \%$, the sensory and motor block action onset times were $18 \pm 6$ and $25 \pm 8$ min, respectively, while $14 \pm 6$ and $24 \pm 8 \mathrm{~min}$ in the ultrasonography group. In our study, sensory and motor block action time was $12.8 \pm 5.5$ and $17.3 \pm 5.4$ min in the NS group, $12 \pm 4.3$ and $15.2 \pm 5.2 \mathrm{~min}$ in the NU group. It was showed that sensory and motor block effect onset times are shorter in our study. This is due to the usage of a higher volume of lidocaine and $2 \%$ prilocaine in our study.

Training is essential for US techniques and takes longer than other techniques. Sandhu and Capan (13) stated that at least 20 procedures should be performed for successful block by ultrasonography. Therefore, all ultrasonographic blockage procedures were performed by an experienced anesthesiologist in our study.

Auroy et al. (14) stated that there is a possibility of developing systemic complications in the range of 0 to 25 at 10,000 according to the applied block type. In contrast, Zetlaoui et al. (15) reported developing generalized seizures in the axillary approach with brachial nerve block using ultrasonography. In this study, the short-term clinical picture after drug injection suggests that intravascular injection was performed.

Liu et al. (16) stated that they did not see systemic and local complications using ultrasonography. In our study, $26.6 \%$ of vascular pneumonectomy was performed in the NS group, and $25 \%$ of these patients had hematomas in their axillary region. In contrast, the vascular puncture was not performed in the NS group. Nevertheless, no systemic complications were encountered in any of our patients.

The frequency of nerve injury in the axillary approach to peripheral block ranges from $0.2 \%$ to $19 \%(17,18)$. In our study, paresthesia was observed in four patients (13.3\%) in the NU group but nine patients (30\%) in the NS group. Less skin fouling affects paresthesia frequency in the $\mathrm{NU}$ group. Nevertheless, none of the patients had neurological complications after the operation.

\section{Study Limitations}

The limitation of our study was that we did not perform a neurological follow-up for a long time after the operation. 


\section{CONCLUSION}

In our study, while ultrasonography was associated with decreased pain and complications associated with the procedure, though not statistically significant, a higher success rate was obtained. Our study results support the routine use of ultrasonography with the NS.

\section{Ethics}

Ethics Committee Approval: Institutional Ethics Committee approval was received for this study from the Local Ethics Committee of İstanbul University, Medical Faculty of İstanbul (decision date: 12/04/2013, decision no: 412).

Informed Consent: Written informed consent was obtained from the patients who participated in this study.

Peer-review: Externally peer-reviewed.

\section{Authorship Contributions}

Concept: D.A., M.T., Design: D.A., Data collection or Processing: D.A., M.S.K., E.A.S., G.D., Analysis or Interpretation: D.A., M.T., Literature Search: D.A., M.S.K., E.A.S., Writing: D.A., G.D.

Conflict of Interest: No conflict of interest was declared by the authors.

Financial Disclosure: The authors declared that this study received no financial support.

\section{REFERENCES}

1. Paul JE, Arya A, Hurlburt L, Cheng J, Thabane L, Tidy A, Murthy Y. Femoral nerve block improves analgesia outcomes after total knee arthroplasty: a meta-analysis of randomized controlled trials. Anesthesiology 2010;113:1144-62.

2. McCartney CJ, Brull R, Chan VW, Katz J, Abbas S, Graham B, et al. Early but no long-term benefit of regional compared with general anesthesia for ambulatory hand surgery. Anesthesiology 2004;101:461-7.

3. Tapar H, Süren M, Kaya Z, Semih A, Karaman S, Kahveci M. Peripheral block anesthesia of upper extremity and its complications. Journal of Contemporary Medicine 2012;2:195-200.

4. Cataldo R, Carassiti M, Costa F, Martuscelli M, Benedetto M, Cancilleri $\mathrm{F}$, et al. Starting with ultrasonography decreases popliteal block performance time in inexperienced hands: a prospective randomized study. BMC Anesthesiol 2012;12:33.
5. Chan VW, Perlas A, McCartney CJ, Brull R, Xu D, Abbas S. Ultrasound guidance improves success rate of axillary brachial plexus block. Can J Anaesth 2007;54:176-82. Erratum in: Can J Anaesth 2007;54:594.

6. Dingemans E, Williams SR, Arcand G, Chouinard P, Harris P, Ruel M, et al. Neurostimulation in ultrasound-guided infraclavicular block: a prospective randomized trial. Anesth Analg 2007;104:1275-80.

7. Song IA, Gil NS, Choi EY, Sim SE, Min SW, Ro YJ, et al. Axillary approach versus the infraclavicular approach in ultrasound-guided brachial plexus block: comparison of anesthetic time. Korean J Anesthesiol 2011;61:12-8.

8. Imasogie N, Ganapathy S, Singh S, Armstrong K, Armstrong P. A prospective, randomized, double-blind comparison of ultrasoundguided axillary brachial plexus blocks using 2 versus 4 injections. Anesth Analg 2010;110:1222-6.

9. Casati A, Danelli G, Baciarello M, Corradi M, Leone S, Di Cianni S, et al. A prospective, randomized comparison between ultrasound and nerve stimulation guidance for multiple injection axillary brachial plexus block. Anesthesiology 2007;106:992-6.

10. Dufour E, Quennesson P, Van Robais AL, Ledon F, Laloë PA, Liu N, et al. Combined ultrasound and neurostimulation guidance for popliteal sciatic nerve block: a prospective, randomized comparison with neurostimulation alone. Anesth Analg 2008;106:1553-8.

11. Perlas A, Brull R, Chan VW, McCartney CJ, Nuica A, Abbas S. Ultrasound guidance improves the success of sciatic nerve block at the popliteal fossa. Reg Anesth Pain Med 2008;33:259-65.

12. Shrestha BR. Nerve stimulation under ultrasound guidance expedites onset of axillary brachial plexus block. J Nepal Health Res Counc 2011;9:145-9.

13. Sandhu NS, Capan LM. Ultrasound-guided infraclavicular brachial plexus block. Br J Anaesth 2002;89:254-9.

14. Auroy Y, Benhamou D, Bargues L, Ecoffey C, Falissard B, Mercier FJ, et al. Major complications of regional anesthesia in France: The SOS Regional Anesthesia Hotline Service. Anesthesiology 2002;97:1274-80.

15. Zetlaoui PJ, Labbe JP, Benhamou D. Ultrasound guidance for axillary plexus block does not prevent intravascular injection. Anesthesiology 2008;108:761.

16. Liu FC, Liou JT, Tsai YF, Li AH, Day YY, Hui YL, et al. Efficacy of ultrasoundguided axillary brachial plexus block: a comparative study with nerve stimulator-guided method. Chang Gung Med J 2005;28:396-402.

17. Stan TC, Krantz MA, Solomon DL, Poulos JG, Chaouki K. The incidence of neurovascular complications following axillary brachial plexus block using a transarterial approach. A prospective study of 1,000 consecutive patients. Reg Anesth 1995;20:486-92.

18. Urban MK, Urquhart B. Evaluation of brachial plexus anesthesia for upper extremity surgery. Reg Anesth 1994;19:175-82. 